\title{
Sustainable territorial development in the context of higher education structure
}

\author{
Elena Kulikova*, Elena Molokova, and Natalia Vlasova \\ Ural State University of Economics, Yekaterinburg, Russia
}

\begin{abstract}
The paper analyzes the impact of the higher education system on territorial development on the basis of modern statistical data. The assessment of the current state of affairs brings out a significant differentiation of regions by the number of universities and students who study there. The formed architecture of the higher education structure does not meet the modern requirements of the spatial development of Russia, contributing to the outflow of talented young people from peripheral regions, provoking uncompensated migration, causing a decrease in the equal accessibility of higher education and the effectiveness of meeting the demand for qualified personnel in regional labor markets. Given the results of the analysis, we draw a conclusion that it is necessary to intensify scientific research in the field in order to develop the latest theory and methodology for synchronizing and harmonizing the interests of the country and its territories.
\end{abstract}

\section{Introduction}

The relevance of exploring the influence of higher education on territorial development is conditioned by the increasing attention to the regional aspects of functioning of the national economy sectors, which is dictated by the growing disproportions in the regions' socioeconomic development, both related to separate phenomena and in general. The development of research into regionalization and spatial differentiation is due, among other things, to the increasing attention and global trends in the recognition of the uniqueness of national and regional cultures.

\section{Methodology}

We should mention that the study is largely based on the works of J. Firman, the classic of the "center-periphery" concept, who proposed a regional development theory. At the same time, at present there is a whole range of scientific approaches to the creation of analytical models of spatial development. Among the practical problems of researching into the regionalization processes of higher education, we should stress the lack of an accepted methodology, and also opposing conceptions of the role of higher education in territorial development. In science, there are at least two conflicting approaches to the study of higher

\footnotetext{
*Corresponding author: e.s.kulikova@mail.ru
} 
education in the context of regional science: the first recognizes its significance and direct impact, the second denies the higher education system to be an object of regional research due to its attribution to the federal jurisdiction.

The authors of this paper adhere to the viewpoint that the system of higher education affects regional development directly and significantly. In order to provide a comprehensive assessment of higher education as a factor of territorial development, we aim to characterize its contemporary system.

\section{Higher Education in Russia}

The structure of vocational education was formed by Federal Law No. 273-FZ "On Education in the Russian Federation", which consolidated its definition and structural elements, including higher education and secondary vocational education. The newest architecture of vocational education was dictated by the inclusion of Russia in the Bologna process, thereby bringing Russian education closer to the International Standard Classification of Education (ISCED), adopted in 2011, where vocational education is called tertiary, corresponding to Levels 5 to 8 .

The contemporary structure of the higher education system in Russia can be represented in the form of a diagram (Figure 1).

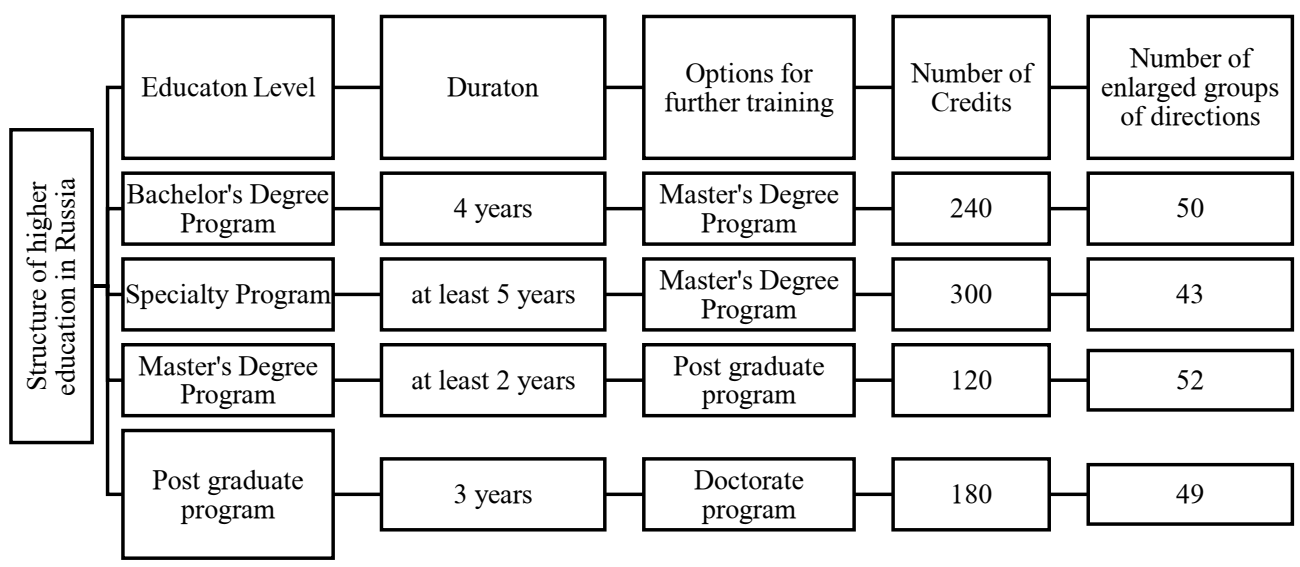

Fig. 1. The contemporary structure of higher education in Russia [1].

At the same time, doctorate programs in Russia are attributed to the field of science and not included in the system of postgraduate higher education.

Most important, the contemporary network structure of higher education organizations cannot be called complete. The total number of higher education organizations is segmented into groups, depending on the goals set by the state, on the range of programs being implemented, and on financial and organizational capabilities (Figure 2).

At the same time, we should stress that the contemporary structure of higher education is subordinated to achieving specific objectives, developing territories being among the key ones. We should also emphasize that the goal of territory development should be provided by the two groups of universities: pivotal and federal ones.

We should agree with the viewpoint that the existing model of supporting regions through the creation of pivotal and federal universities is untenable, since they still could not compete with the "central universities" of Moscow and St. Petersburg [3], for which the brightest graduates of municipal schools regularly leave. 


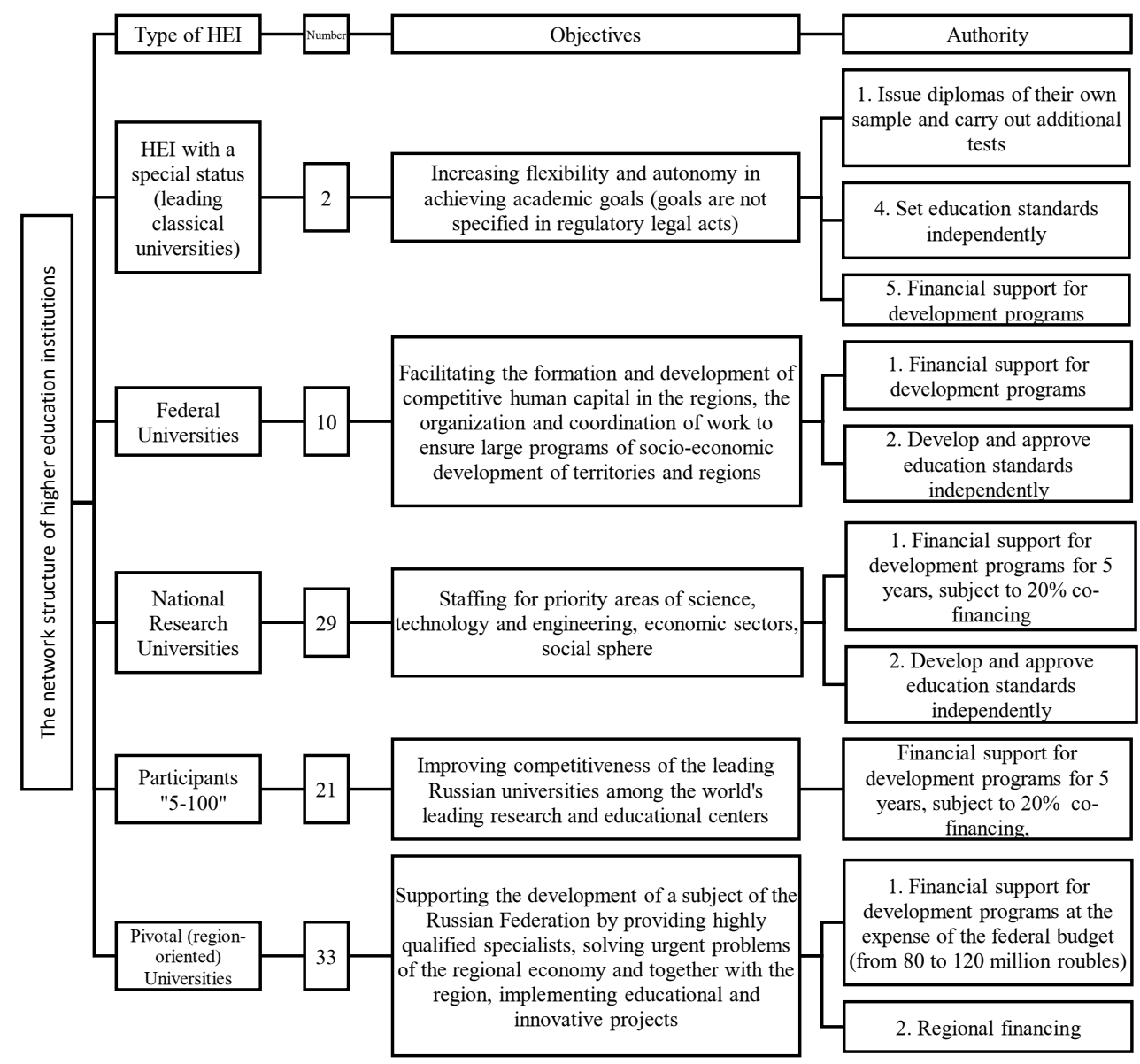

Fig. 2. The network structure of higher education institutions (HEI)

Currently, the status of pivotal universities has been obtained by educational organizations of thirty-three regions of Russia. This status is assigned to educational organizations that have adopted a self-development program, synchronized with the goals of socio-economic development of the given region. The university is to implement the program, with the government funding being insufficient.

The contemporary system of higher education includes 724 institutions of higher education of various subordination levels.

We should stress that the density of students varies significantly by the territories (Figure 3). 


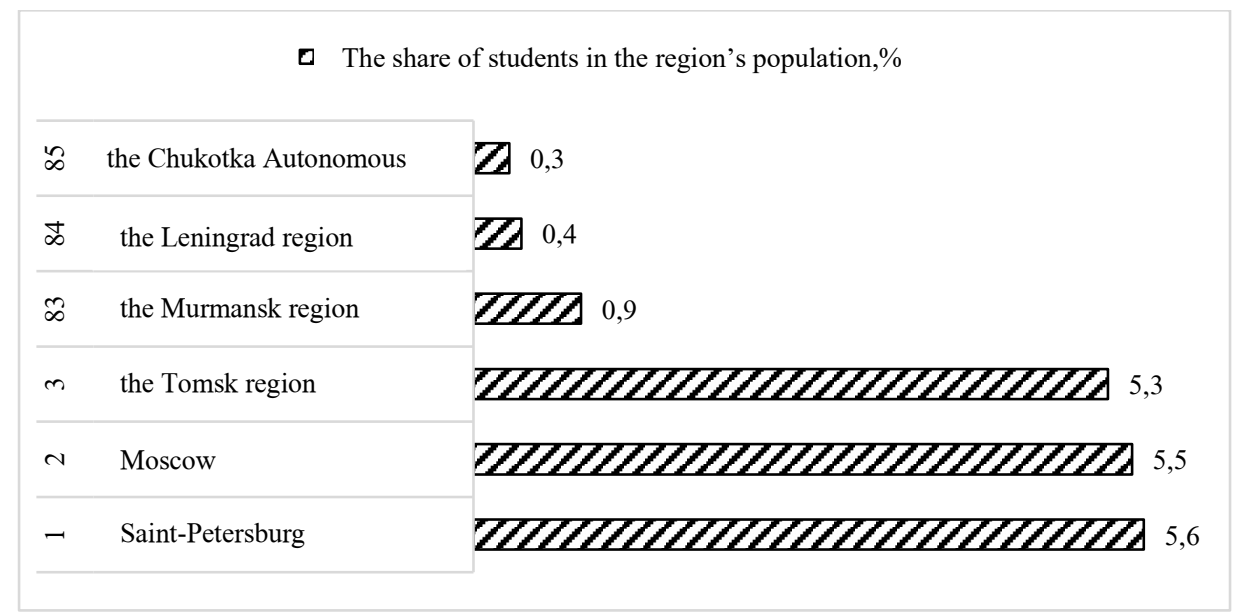

Fig. 1. Regions with the highest and lowest student density per capita,\% (on the left is the ranking of regions) [2].

At the same time, the regions' attractiveness for students is compatible with the interest in employment in large Russia's centers. Thus, the described situation leads to an outflow of both labor resources and talented school-leavers from the periphery. We should also state that the described problem was largely provoked by the introduction of a unified state examination (USE), which increased the availability of central universities for residents of the periphery.

The problem is aggravated by a significant difference in the number of educational organizations in the regions (Figure 4).

\section{Results}

The analysis of the number of educational institutions of higher education allows us to note that only fifteen regions of Russia have more than ten universities on their territory, while twenty subjects of the Russian Federation have only one or two educational institutions of higher education. At the same time, $20 \%$ of universities are located in Moscow and almost $9 \%$ - in St. Petersburg; in total, half of all universities in the country are concentrated in a dozen regions.
The Republic of Dagestan the Voronezh region the Novosibirsk region the Samara region the Krasnodar region the Republic of Tatarstan the Sverdlovsk region the Moscow region Saint-Petersburg Moscow

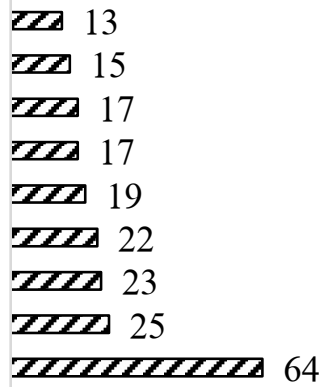

$Z Z Z Z Z Z Z Z Z Z Z Z Z Z Z Z Z Z Z Z Z Z Z Z Z Z Z Z 146$

Fig. 2. Top 10 regions by the number of higher education institutions [2]. 
There is also a significant differentiation in the number of students, $50 \%$ of whom study in 12 regions of Russia (Figure 5). To be more specific, 699,843 students study in Moscow, 302,616 in St. Petersburg; the Nizhny Novgorod region closes the top ten with 83 thousand students studying there [2].

The foregoing enables us to draw a conclusion about the uneven spatial placement of higher education institutions and students who study there, which significantly affects the availability of higher education.

We should also emphasize the existence of regional differentiation in the context of the territory type. Currently, there is a disparity in the proportion of urban and rural residents having higher education, the indicator in rural areas being significantly lower (twice as low).

\section{Conclusions}

The assessment of the higher education system development carried out in the present study enables to identify a set of current problems that significantly affect the progressive territorial development. Among the main problems we can highlight the following ones:

- first, with the implementation of state control and supervisory measures in 20132017 , in the context of a significant reduction of universities, the equal access to higher education for peripheral territories has decreased;

- second, the reduction that took place according to the results of the universities' effectiveness monitoring did not take into account the low mobility of the population, the small number of higher education organizations in specific territories, as well as the significant difference in the income of the population of the center and peripheral territories, which provoked regional differentiation and significant interregional uncompensated migration;

- third, the transformation of the higher education system has failed to increase the efficiency of meeting the demand for qualified personnel in regional labor markets, which, together with the two above trends, provokes an outflow of highly qualified workers to the central regions;

- fourth, despite the segmentation of universities for solving specific problems, the possibility to take into account the regional characteristics of the labor market, demography, and socio-economic conditions, on the whole has decreased.

Thus, we can state that the existing architecture of higher education is not optimal for regional development and requires the elaboration of a theory and methodology for synchronizing socio-economic processes in the regions and the federation.

\section{References}

1. On education in the Russian Federation: Feder. Law of December 29, 2012 No. 273-FZ (as amended on December 2, 2019), http://www.pravo.gov.ru

2. Statistical information in the field of research and development and in the field of higher education. Higher education. M-in science and higher education Ros. Federation, https://minobrnauki.gov.ru/

3. Universities at a Crossroads: Higher Education in Russia, ed. D. P. Platonova, Ya. I. Kuzminova, I. D. Frumin; Nat. issled. un-t "Higher School of Economics", Institute of Education, House of the Higher School of Economics, 319 (2019)

4. E. Abad-Segura, M. González-Zamar, J. C. Infante-Moro, G. R. García, Sustainability, 12(5) (2020) 
5. A. M. Aleixo, S. Leal, U. M. Azeiteiro, J. of Cleaner Production, 172, 1664 (2018)

6. I. I. Berchin, M. Sima, M.A. de Lima, S. Biesel, L. P. dos Santos, R. V. Ferreira, F. Ceci, J. of Cleaner Production, 171, 756 (2018)

7. L. Daniela, A. Visvizi, C. Gutiérrez-Braojos, M.D. Lytras, Sustainability, 10(11) (2018)

8. F. Findler, N. Schönherr, R. Lozano, D. Reider, A. Martinuzzi, Int. J. of Sustainability in Higher Education, 20(1), 23 (2019)

9. F. Findler, N. Schönherr, R. Lozano, B. Stacherl, Sustainability, 11(1) (2018)

10. E. Fleacă, B. Fleacă, S. Maiduc, Sustainability, 10(4) (2018)

11. Franco, O. Saito, P. Vaughter, J. Whereat, N. Kanie, K. Takemoto, Sustainability Science, 14(6), 1621 (2019)

12. Gontareva, B. Maryna, V. Babenko, I. Perevozova, A. Mokhnenko, WSEAS Transactions on Environment and Development, 15, 593 (2019).

13. P. Hallinger, C. Chatpinyakoop, Sustainability, 11(8) (2019)

14. Molderez, E. Fonseca, J. of Cleaner Production, 172, 4397 (2018)

15. N. Parvez, A. Agrawal, J. of Cleaner Production, 214, 975 (2019)

16. G. Sonetti, M. Brown, E. Naboni, Sustainability, 11(1) (2019)

17. V.R. Vargas, R. Lawthom, A. Prowse, S. Randles, K. Tzoulas, J. of Cleaner Production, 208, 470 (2018)

18. R. Winzer, L. Lindberg, K. Guldbrandsson, A. Sidorchuk, PeerJ, 4 (2018) 